\title{
Phenomena-Based Process Synthesis and Design to Achieve Process Intensification
}

Lutze, Philip; Gani, Rafiqul; Woodley, John

Publication date:

2011

Link back to DTU Orbit

Citation (APA):

Lutze, P., Gani, R., \& Woodley, J. (2011). Phenomena-Based Process Synthesis and Design to Achieve Process Intensification. Abstract from 2011 AlChE Spring Meeting, Chicago, IL, United States.

\section{General rights}

Copyright and moral rights for the publications made accessible in the public portal are retained by the authors and/or other copyright owners and it is a condition of accessing publications that users recognise and abide by the legal requirements associated with these rights.

- Users may download and print one copy of any publication from the public portal for the purpose of private study or research.

- You may not further distribute the material or use it for any profit-making activity or commercial gain

- You may freely distribute the URL identifying the publication in the public portal

If you believe that this document breaches copyright please contact us providing details, and we will remove access to the work immediately and investigate your claim. 


\title{
Phenomena-Based Process Synthesis and Design to Achieve Process Intensification
}

\author{
Philip Lutze ${ }^{a}$, Rafiqul Gani ${ }^{b}$ and John M. Woodley ${ }^{a}$ \\ ${ }^{a}$ PROCESS, Department of Chemical \& Biochemical Engineering, Technical University of Denmark, \\ DK-2800 Lyngby, Denmark \\ ${ }^{b}$ CAPEC, Department of Chemical \& Biochemical Engineering, Technical University of Denmark, \\ DK-2800 Lyngby, Denmark
}

In recent years, Process Intensification (PI) has attracted considerable interest as a potential means of process improvements and to meet the increasing demands for sustainable production. PI aims to improve processes by increasing efficiency, reducing energy consumption, operational costs, volume, and waste as well as simplifying the flowsheet. A variety of intensified operations and equipment has been developed. Potentially, this creates a large number of options for possible process improvement, however, to date only a limited number of intensified technologies have achieved implementation, such as reactive distillation, dividing wall columns and reverse flow reactors [1]. One major reason for this is that the identification of the best PI option is neither simple nor systematic.

In previous work [2] we reported the development of a general computer-aided systematic synthesis and design methodology in which redundant intensified options are systematically removed by checking against predefined constraints through a decomposition approach of a superstructure optimization problem. In this approach lower level steps employ simple and easy calculations, while the higher level steps employ more rigorous and detailed calculations. However, up to now, this methodology is limited to already reported PI unit operations which can be retrieved, together with all information necessary for synthesis and design of each of them, from a knowledge base tool. In order to invent new unit operations going beyond those currently in existence, process synthesis and design incorporating PI needs to be investigated at the phenomenological level $[3,4]$ which will be presented in this contribution. The basis of the phenomena-based process synthesis is transfer units consisting of mass, component, energy and momentum balances as well as phenomena building blocks and model equations describing them. Following the same rationale as the general methodology described previously, the problem is first defined, given a set of product quality and quantity as well as additional process constraints in addition to the potential need for the improvement. Next, the given information is analyzed to identify all potential phenomena building blocks. In the next step, the phenomena building blocks are joined together according to combination rules to match process intensification targets defined through a superstructure of flowsheet options. Based on these, the generated options are screened through performance specifications before unit operations are identified. For example, a counter-current sequence of similar simultaneous mixing and vapour-liquid phenomena with the final steps at both ends being simultaneous heat transfer, mixing and vapour-liquid phase change phenomena can be identified as a distillation column. In the penultimate step, the remaining options are optimized with respect to a defined objective function. The results are verified through rigorous model simulations in the final step. The advantage of the phenomena-based process synthesis and design is that it generates potentially novel process options because the initial search space is wider than the search space of existing 
units (truly predictive models lead to reliable predictive solutions) as well as the simultaneous development of the necessary process models.

In this contribution the application of a phenomena-based process synthesis combined with a systematic methodology through a computer-aided framework will be described and highlighted with selected examples in the area of distillation systems, together with a focus on some of the suitable methods and tools.

[1] Harmsen, J. Process Intensification in the petrochemicals industry: Drivers and hurdles for commercial implementation. Chem Eng Process 2010; 49, 1, 70-73.

[2] Lutze, P., Gani, R., Woodley, J.M. Process Intensification: A perspective on process synthesis. Chem Eng Process 2010; 49, 6, 547-558.

[3] Freund, H., Sundmacher, K. Towards a methodology for the systematic analysis and design of efficient chemical processes: Part 1 . From unit operations to elementary process functions. Chem Eng Process 2008; 47, 12, 2051-2060.

[4] Papalexandri, K.P., Pistikopoulos, E.N. Generalized modular representation framework for processs synthesis. AIChE J 1996; 42, 4, 1010-1032 